\title{
Interjeksi dalam Bahasa Arab
}

\author{
Sahara Ramadhani \\ Universitas Gajah Mada Yogyakarta \\ sahara.ramadhani@mail.ugm.ac.id \\ DOI: http://dx.doi.org/10.18326/lisania.v2i1.1-12
}

\begin{abstract}
Interjection is the words used to show expressions spontaneously. Each language has different forms of interjection. This study aims to provide a comprehensive overview of the intermediate form in Arabic. The data used in this study is written data in the form of Arabic novels and drama script. The data is obtained by the attentive observation method. The basic technique used is tapping technique. The advanced technique is by using the note technique. The methods used for the data analysis are distribution and contextual method. The results of the analysis show that based on the form of Arabic interjections, it can be grouped into primary forms, secondary forms, phrase form, and clause form.
\end{abstract}

Keywords: Interjection, Arabic, Contextual

\begin{abstract}
Abstrak
Interjeksi merupakan kata-kata yang digunakan untuk menunjukkan ekspresi secara spontan. Setiap bahasa memiliki bentuk interjeksi yang berbeda-beda. Penelitian ini bertujuan untuk memberikan gambaran secara menyeluruh mengenai bentuk interjeksi dalam bahasa Arab. Data yang dipergunakan dalam penelitian ini adalah data tertulis yang berupa novel dan naskah drama Arab. Data tersebut diperoleh dengan metode simak. Teknik dasar yang digunakan adalah teknik sadap. Adapun teknik lanjutannya menggunakan teknik catat. Metode yang dipergunakan untuk menganalisis data adalah metode distribusi dan metode kontekstual. Hasil analisis menunjukkan bahwa berdasarkan bentuknya interjeksi bahasa Arab dapat dikelompokkan menjadi bentuk primer, bentuk sekunder, bentuk frasa, dan bentuk klausa.
\end{abstract}

Kata kunci: Interjeksi, Bahasa Arab, Kontekstual 


\section{Pendahuluan}

Interjeksi merupakan bentuk ungkapan perasaan yang ada dalam hati pembicara. Untuk memperkuat rasa hati seperti terkejut, kagum, sedih, heran, dan jijik seseorang akan memakai kata tertentu disamping kalimat yang mengandung makna pokok yang dimaksud. Secara struktur interjeksi tidak bertalian dengan unsur kalimat yang lain (Moeliono, 2003: 203). Kridalaksana (2005: 120) mengidentifikasikan interjeksi sebagai kategori yang bertugas mengungkapkan perasaan pembicara dan secara sintaksis tidak berhubungan dengan kata-kata lain dalam ujaran. Interjeksi bersifat ekstra kalimat dan selalu mendahului ujaran sebagai teriakan yang lepas atau berdiri sendiri.

Ameka (1994: 743) membagi bentuk interjeksi menjadi dua yaitu primary (primer) dan secondary (sekunder) interjection. Interjeksi primer adalah kata-kata pendek atau nonwords yang dalam distribusinya dapat berupa ujaran noneliptikal bebas dan tidak termasuk dalam kelas kata lain, misalnya dalam bahasa Inggris, gee, oops, dalam bahasa Indonesia hah, $a h$, eh dan lain-lain. Interjeksi sekunder adalah kata-kata yang memiliki makna semantik bebas, namun dapat digunakan secara konvensional sebagai ujaran noneliptikal yang bebas untuk mengekspresikan tindakan atau pernyataan mental penuturnya, misalnya panggilan minta bantuan atau dalam keadaan bahaya seperti help, fire dalam bahasa Inggris dan tolong dalam bahasa Indonesia, makian atau kata tabu fuck, sial dalam bahasa indonesia. Adapun Wilkins (2009:73) melihat bentuk interjeksi lebih lengkap dengan membagi bentuk interjeksi atas bentuk primer, sekunder, frasa, dan klausa. Berdasarkan data yang ditemukan peneliti, interjeksi dalam bahasa Arab dapat berupa bentuk primer, bentuk sekunder, bentuk frasa, dan bentuk klausa. Beberapa interjeksi juga memiliki multifungsi dalam komunikasi tergantung konteks pengucapannya.

Penelitian ini akan berusaha mengembangkan teori interjeksi bahasa Arab yang menyebutkan bahwa interjeksi bahasa Arab hanya terbatas pada pola dan bentukbentuk tertentu. Selanjutnya penelitian ini akan berusaha merumuskan tidak hanya mengenai bentuk interjeksi, akan tetapi penelitian ini akan membahas klasifikasi interjeksi yang mencakup makna dan fungsi, serta interjeksi yang memiliki multifungsi dalam Bahasa Arab dengan lebih komprehensif. 


\section{Metodologi Penelitian}

Pada tahap penyediaan data digunakan metode simak, yaitu penyediaan data dengan menyimak penggunaan bahasa Arab pada sumber data yang berupa naskah drama, cerpen, dan novel Arab. Selanjutnya penulis menggunakan teknik dasar, yaitu teknik sadap. Penyadapan dilakukan dengan membaca data untuk kemudian menggunakan bolpoin merah sebagai penanda data interjeksi. Adapun teknik lanjutan yang digunakan adalah teknik catat, yaitu penulis mencatat semua penggunaan interjeksi, yang dilanjutkan dengan transkripsi ortografis pada kartu data.

Data interjeksi yang telah terkumpul dianalisis untuk mendapatkan gambaran yang diinginkan. Untuk menjawab rumusan masalah penelitian ini menggunakan metode distribusi. Metode ini digunakan untuk menentukan data tersebut termasuk interjeksi atau bukan. Adapun teknik yang dipergunakan adalah teknik lesap. Dalam penelitian ini, teknik lesap bertujuan untuk membuktikan kadar keintian interjeksi dalam suatu kalimat.

\section{Definisi Interjeksi Bahasa Arab}

Wierzbicka (1991: 290) mendefinisikan interjeksi sebagai sebuah tanda linguistik. Tanda itu harus memenuhi beberapa kriteria kondisi, antara lain: dapat berdiri sendiri dalam penggunaannya, mengekspresikan makna tertentu, tidak termasuk ke dalam tanda lain, tidak homofon dengan bentuk leksikal lain yang secara semantik berkaitan dan merupakan pernyataan mental atau tindakan mental yang spontan dari penutur.

Dalam bahasa Arab, interjeksi termasuk kategori kalimat eksklamatif yang disebut ta'ajjub. Dalam al-mu'jam al-wasît (Wahbah, 1984: 110) disebutkan bahwa ta'ajjub adalah memandang hal yang nampak keistimewaannya tetapi tidak diketahui sebabnya. Adapun menurut Ar-Raqr (1986: 154) ta'ajjub merupakan perasaan dalam jiwa ketika merasakan sesuatu yang tidak dipahami sebabnya. Babti (2004: 355), mengatakan bahwa ta'ajjub adalah perasaan yang mempengaruhi jiwa ketika merasakan kebesaran sesuatu yang tidak lazim atau tiada bandingannya, yang tidak dapat dimengerti hakikatnya atau tidak dipahami sebabnya. Ta'ajjub dalam bahasa Arab, dapat berbentuk pola mâ af'alahu, af'il bihi atau dapat didahului oleh partikel seru (interjeksi) dalam berbagai bentuk. 
Ameka (1994: 743) membagi bentuk interjeksi menjadi dua, yaitu primary (primer) dan secondary (sekunder) interjection. Adapun Wierzbicka menganggap bahwa bentuk interjeksi hanyalah bentuk primer. Interjeksi bentuk sekunder tidak dianggap sebagai bentuk interjeksi karena menempati fungsi leksikal tertentu dan memiliki independensi semantis. Sementara Wilkins (2009: 73) melihat bentuk interjeksi lebih lengkap dengan membegi bentuk interjeksi atas bentuk primer, sekunder, frasa, dan klausa. Dalam penelitian ini penulis mengacu pada bentuk interjeksi yang dikemukakan oleh Wilkins (2009) karena sangat relevan dengan data penelitian interjeksi bahasa Arab.

\section{Bentuk Interjeksi Bahasa Arab}

Secara garis besar, interjeksi dalam bahasa Arab dapat dikelompokkan sekurangkurangnya menjadi empat, yaitu: interjeksi bentuk primer, bentuk sekunder, bentuk frasa, dan bentuk klausa.

\section{Bentuk primer (Primary Interjection)}

Bentuk interjeksi primer merupakan kata-kata pendek yang dapat berupa ujaran noneliptikal bebas dan tidak termasuk dalam kelas kata lain (Ameka, 1994: 743). Interjeksi primer berhubungan dengan makna gramatikal. Interjeksi tersebut tidak memiliki makna secara leksikal, akan tetapi apabila dimasukkan ke dalam sebuah kalimat akan memunculkan makna dari interjeksi tersebut. Adapun interjeksi primer dalam bahasa Arab yang ditemukan oleh penulis adalah hâ, hyah, hah, yâh, dan hûh. Perhatikan data berikut ini.

\footnotetext{
Abu Shafwan : "Satarâ minnî mâ yasurruka, in syâ allâh".

'Ibâd : "Hâ! Hum al-mushallûna qad bada'û yakhrujûna, tafarraqû alâna qalîlan tsumma tadkhulûna fí ash-shaffi al-awwali".

Artinya:

Abu Shafwan :Engkau akan melihat bagaimana aku membuatmu bahagia, Jika Allah mengizinkan"

Ibâd : : "Ha! Mereka orang-orang yang salat mulai keluar, berpencarlah sebentar lalu berbarislah di baris pertama!" (Bākasiīr, 1951: 74).

Pada data di atas, interjeksi hâ merupakan interjeksi primer. Interjeksi hâ ini tidak memiliki makna leksikal, akan tetapi ketika interjeksi tersebut masuk ke dalam kalimat, maka akan muncul maknanya. Interjeksi ini dalam konteks data di atas menunjukkan ekspresi rasa terkejut penutur, yaitu Ibad.
} 


\section{Bentuk Sekunder (Secondary Interjection)}

Bentuk interjeksi sekunder yang terdapat dalam bahasa Arab terdiri dari kalimah (kata). Adapun kata yang digunakan sebagai interjeksi bahasa Arab berupa ism yang meliputi nomina maushûf (kata yang dapat disifati) dan nomina shifah (adjektiva), ismu al-fi'li (noun verb) dan berupa harfu an-nidâ’ (partikel nidâ').

\section{Nomina Al-Maushûf}

Nomina al-maushûf merupakan suatu kata yang mengacu pada suatu dzat atau hakikat sesuatu dan lafadz tersebut dibentuk untuk dapat diberi sifat (al-Ghulâyaini, 2010: 97, Ad-Dahdah, 1993: 338). Pada penelitian ini, diperoleh interjeksi yang berupa kata nomina al-maushûf, yaitu himârun, khinzîr, dan kalbun. Berikut penjelasan mengenai interjeksi sekunder yang berupa nomina al-maushûf.

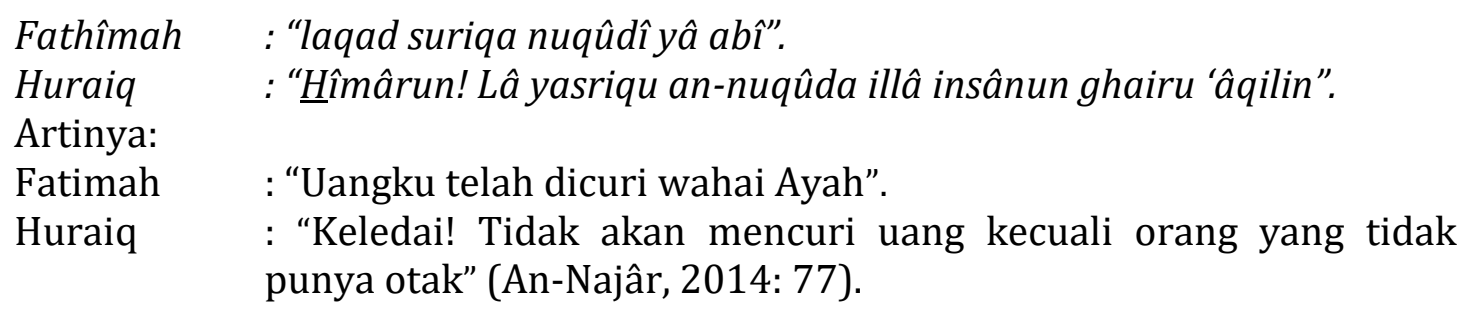

Pada data di atas, kata himârun yang berarti 'keledai' merupakan salah satu interjeksi sekunder yang menempati kelas kata benda (nomina) yang berbentuk nomina al-maushûf dan digunakan sebagai kata makian yang mengungkapkan ekspresi kekesalan penutur. Kata himârun termasuk nomina tidak tentu berkasus nominatif (nakirah/indeterminate) dikarenakan ditandai oleh tanwin dan harakat dhammah (vocal /u/) pada akhir kata. Kata himârun termasuk interjeksi karena tidak mengandung makna leksikal dari kata himârun yaitu 'keledai', akan tetapi berfungsi sebagai penanda rasa marah.

\section{Nomina Ash-Shifah}

Nomina ash-shifah (adjektiva) adalah suatu kata yang mengandung makna sifat/adjektiva (al-Ghulâyaini, 2010: 97, Ad-Dahdah, 1993: 338). Adapun interjeksi yang berbentuk nomina ash-shifah yang ditemukan peneliti adalah thayyîbun, hasanun, 'ajîbun, majnûn, 'azîmun, miskînun, la'natun, jamîlun, shahîhun, tamâmun, mabrûkun, khairun, khabîtsun, mal'ûnatun, khâ'inun, dan hamqâ'u. Berikut adalah data interjeksi tersebut. 
Ar-rajulu

Al-mar'at

Artinya:

Seorang laki-laki

Seorang perempuan
: "Lima lâ? innahum yas'alûna al-mahkûm 'alaihi bi al i'dâmi 'an raghbatihi al-akhîrati".

: "Majnûnun!"

: "Kenapa tidak? Mereka bertanya kepada narapidana eksekusi mati tentang keinginan terakhirnya".

: "Gila!" (Mahfûdz, 2008: 93).

Pada data di atas, kata Majnûnun yang berarti 'gila' merupakan salah satu interjeksi sekunder karena dapat menempati kelas kata nomina yang berbentuk nomina ash-shifah (adjektiva) dan dipergunakan sebagai kata makian yang mengungkapkan ekspresi rasa marah penutur. Interjeksi Majnûnun 'gila' ini termasuk shifah mufrad yang berbentuk ismu al-maf'ûl (patient noun) yaitu shifah yang diambil dari fi'il majhûl (verb passive) untuk menunjukkan adanya perbuatan atas sesuatu yang disifati dalam hal perbuatan atau kejadian ( $\underline{h} u d \hat{u} t s)$ bukan keadaan yang tetap atau terus menerus (alGhulâyainî, 1972: 189). Kata Majnûunun dari verba janna 'menjadi gelap' yang dimajhulkan menjadi mujnânun dan menjadi ismu al-maf'ûl berupa Majnûnun.

\section{Ismu Al- Fi'l}

Ismu al- fi'li merupakan kata yang menunjukkan atas sesuatu yang menunjukkan atas sesuatu yang ditunjukki oleh fi'il namun ismu al- fi'li tersebut tidak dapat menerima alamat (tanda-tanda) fi'il (al-Ghulâyaini, 2010: 97). Ismu al- fi'li adakalanya memiliki makna al-fi'lu al-madhî (verba perfect), al-fi'lu al-mudhâri' (verba imperfect), dan fi'lu al-amr (verba imperative). Interjeksi isim fi'il yang ditemukan oleh peneliti adalah way, âmîn, shah, mah, âh, uffin, wâ, îh, dan hayya. Perhatikan data berikut ini.

Abu Shafwan : "Fawadhaha annahu kâna ya'nî rajulan min al-'ulamâ'i yaqdiru an yaksyifa linnâsi jahlaka!."

Juhâa : "Way! Ka'annahum jầû bika ilâ hun^a litaksyifa linnâsi al-jâhiliy".

Artinya:

Abu Shafwan : "Kalau begitu jelas bahwa dia adalah lelaki yang merupakan ulama yang mampu menyingkap kebodohanmu kepada masyarakat

Juha : "Way! seolah-olah mereka mendatangkanmu kesini untuk membongkar kebodohanku kepada mereka” (Bâkatsîr, 1951: 14).

Pada data di atas, kata wai merupakan interjeksi sekunder yang berbentuk ismu al- fi'li karena merupakan kata yang berbentuk nomina, akan tetapi memiliki makna alfi'l al-mudhâri' (verba imperfect) ata'ajjabu 'saya heran'. 


\section{Partikel Nidố' (Harfu An-Nidấ')}

Harfu an-nidâ' merupakan partikel yang digunakan untuk memanggil atau memperingatkan seseorang atau kelompok untuk melaksanakan dan memperhatikannya (Al-Ghulâyaini, 2010: 109). Harfu an-nidâ' yang berfungsi sebagai interjeksi ada tujuh, yaitu $a$, ay, yô, $\hat{a}$, ayâ, hayâ, dan wâ. Perhatikan data berikut ini.

"Ay Waladiy, lâ taksal!."

Artinya:

“Wahai anakku, jangan malas!” (Ya'qûb, 1996: 11).

“A Khâlidu, ajib!.”

Artinya:

“Wahai Khalid, jawab!”(Ya'qûb, 1996: 20).

Pada data di atas partikel (harf) Ay 'wahai' dan A 'wahai' merupakan partikel yang digunakan sebagai interjeksi panggilan dalam bahasa Arab yang dipergunakan untuk memanggil sesuatu yang dekat.

\section{Interjeksi Berbentuk Frasa}

Interjeksi bentuk frasa yang biasa digunakan oleh penutur Arab hanya terdapat 3 macam bentuk frasa, yakni murakkab idhâfiy, murakkab washfiy dan frasa preposisi (al-jarr wa al-majrûr). Berikut adalah penjelasan lebih lanjut mengenai interjeksi tersebut.

\section{Murakkab Idhâfiy (Genitive Construction)}

Murakkab Idhâfiy didefinisikan sebagai kata yang tersusun dari mudhâf (governing word) dan mudhâf ilaih (governed of a genitive construction) (Al-Gulâyaini, 2010:9). Adapun interjeksi yang berbentuk murakkab Idhâfiy yang ditemukan peneliti, yaitu ra`su al-fasâdi, syaikhu as-sû̉i, qalîlu al-hayầi, bintu al-lu 'ûm, rabbus as-samâwâti, ma'âdzallâh, ghairu ma'qûlin, qabbâhu ar-rajuli, bi'sa al-fa'âl. Berikut adalah data dari interjeksi tersebut.

Al-fatâtu : : "atarisyûnî yâ rajulun murtakiban bizalika jarîmatin tsâlitsatin?".

Ar-rajulu : "Ma'âdzallâh. walakinnanî a'dâ haqqa ad-daulati 'alayya".

Artinya:

Seorang gadis : "Wahai lelaki, kau menyuapku untuk pelaku dengan tiga kejahatan?".

Seorang laki-laki : "Perlindungan Allah. Tetapi aku hanya melakukan kewajiban pemerintah yang diberikan kepadaku" (Mahfûdz, 2014: 53). 
Ungkapan Ma'âdzallâh pada data di atas merupakan interjeksi berbentuk frasa dengan pola idhāfiy. Kata Ma'âdza 'perlindungan' berfungsi sebagai mudhâf (unsur inti) dan Allah 'Allah' berfungsi sebagai mudhâf ilaih (unsur modifikator). Pada data tersebut kata Ma'âdzallâh 'perlindungan Allah' mengungkapkan ekspresi keheranan.

\section{Murakkab Washfiy}

Murakkab Washfiy didefinisikan sebagai struktur kata yang tersusun dari dua nomina. Nomina pertama menjelaskan nomina kedua. Adapun nomina pertama disebut dengan maushûf (qualified noun/described noun) dan nomina kedua disebut dengan shifah (adjektiva) (Al-Gulâyaini, 2010: 9). Adapun interjeksi berupa murakkab washfìy yang ditemukan oleh peneliti, yaitu hayawânun shahîhun dan ghadârun khâinun. Berikut adalah data interjeksi yang berbentuk Murakkab Idhâfiy.

Syâdan : "Thalaba minnî an as`aluka bimiliyûni dûlaran".

Sâlim : "hayawânun shahîhun! hal nasîta".

Artinya:

Syadan : "Izinkan aku untuk bertanya kepadamu mengenai uang sejuta dollar itu".

Salim : "Hewan yang benar! Apakah kamu lupa?” (An-Najâr, 2014: 45).

Ungkapan Hayawânun shahîhun pada data di atas merupakan interjeksi berbentuk frasa dengan pola murakkab wasfiy. Kata hayawânun 'hewan' sebagai maushûf (qualified noun) dan kata shahîhun 'benar` sebagai shifah (adjektiva). Struktur hayawânun shahîhun 'hewan yang benar' mengandung dua nomina. Nomina kedua shahîhun 'benar' merupakan sifat (adjektiva) dari nomina yang diikuti hayawânun 'hewan`. Hayawânun shahîhhun 'hewan yang benar' merupakan salah satu interjeksi berbentuk frasa yang menunjukkan ekspresi kekesalan penutur.

\section{Frasa Preposisional (al-Jarr wa al-Majrûr)}

Frasa preposisional adalah frasa yang yang ditandai oleh hadirnya preposisi atau kata depan pada bagian awal. Preposisi dalam bahasa Arab adalah semua harf al-jarr dan sebagian dzaraf yang merupakan nomina dalam bahasa Arab. Data interjeksi berbentuk frasa preposisional (jarr-majrûr) yang ditemukan peneliti, yaitu wallâhi, billâhi, tallâhi, ma'a as-salâmati, bi idznillâhi. Berikut adalah data dari interjeksi tersebut. 


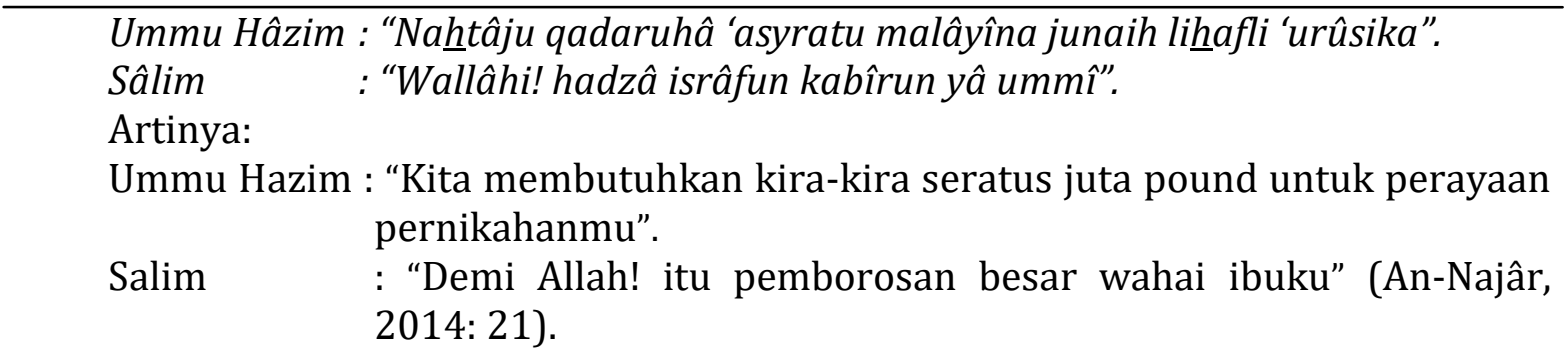

Ungkapan Wallâhi pada data di atas merupakan interjeksi berbentuk frasa preposisional. Partikel (harf) wa 'demi` sebagai preposisi (harf al-jarr) dan kata Allâh (ism 'âlam) sebagai majrûr. Wallâhi 'demi Allah' merupakan salah satu interjeksi berbentuk frasa yang menunjukkan ekspresi keterkejutan penutur.

\section{Konstruksi Nida (partikel nidâ' dan nomina Munâdâ)}

Konstruksi nidâ' merupakan gabungan antara huruf nidâ' dan nomina Munâdâ. Harfu an-nidâ' merupakan partikel yang digunakan untuk memanggil atau memperingatkan seseorang atau kelompok untuk melaksanakan dan memperhatikannya (Al-Ghulâyainî, 2010: 211). Adapun munada merupakan nomina yang terletak setelah harfu an- nidâ’: Data interjeksi berbentuk konstruksi nidâ' yang ditemukan peneliti, yaitu ya Allâh, yâ rabb, yâ ilâhi, yâ salâm, ya rahmân, ya rahîm, ya lathîf, dan ya hayyu ya qayyûm. Berikut adalah data dari interjeksi tersebut.

As-syaikh : "Lâ ba`sa. Kullu an-nisâ'i yatawajja'na atsnâ'a al-wilâdati. Wa lâ tansa anna hadzihi hiya wilâdatuhâ al-bikr".

Asy-syâbb : "Yâ Allâh, yanbaghî an a'ûdu ilaihâ".

Artinya:

Guru : "Tidak apa-apa setiap wanita merasakan sakit sepanjang proses melahirkan. Dan jangan lupa ini adalah proses melahirkan seorang gadis".

Pemuda : "Ya Allah, aku harus kembali kepadanya” (Sa’îd, 2004: 65).

Ungkapan Ya Allah pada data di atas merupakan interjeksi berbentuk konstruksi nidâ' : Dalam gabungan kata tersebut, partikel nidâ' (harf nidâ') ya 'wahai bergabung bersama kata Allah 'Allah' (nomina munâdâ). Pada data itu, kata Yâ Allâh merupakan salah satu interjeksi sekunder ekspresi rasa sedih yang dikarenakan penyesalan akan terjadinya sesuatu. 


\section{Interjeksi Berbentuk Klausa}

Interjeksi dalam bahasa Arab juga dapat terdiri dari susunan kata yang dapat membentuk jumlah (klausa), yaitu jumlah ismiyyah dan jumlah fi'liyyah.

\section{Jumlah Ismiyyah}

Jumlah ismiyyah didefinisikan sebagai jumlah yang diawali ism (nomina) (alKhuli, 1982: 184). Adapun interjeksi yang berbentuk jumlah ismiyyah yang ditemukan oleh peneliti yaitu Allâhu a'lamu, Allâhu ma'aki, Allâhu akbar, Alhamdu lillâhi, la'natullâhi 'alaika, Wailaka, Waihaka dan Wazan mâ af'ala (mâ asyadda, mâ ahlâ, mâ a'dhama, mâ ab'atsa, mâ atsqala, mâ arhafa, mâ adzrafa, mâ ab'ada, mâ althafa). Berikut adalah data interjeksi yang berbentuk jumlah ismiyyah.

Hâzim : "Urîdu an athmainna 'alaika yâ jaddî”.

Al-jaddu : "Alhamdulillâh 'alâ kulli hâl".

Artinya:

Hazim : “Aku ingin memberi ketenangan padamu wahai kakekku”.

Kakek : "Segala puji bagi Allah atas semua keadaan ini" (An-Najjâr, 2014:25).

Ungkapan Alhamdulillâh pada data di atas merupakan interjeksi berbentuk klausa yang berupa Jumlah ismiyyah. Kata alhamdu merupakan ism (nomina) yang menduduki posisi mubtada' (realisasi subjek). Adapun predikatnya berupa khabar berupa jarr majrûr (frasa preposisional) karena terdiri dari lam sebagai huruf jarr (preposisi) dan Allâh (ism 'âlam) sebagai majrûr. Interjeksi Alhamdulillâh 'segala puji bagi Allah' merupakan salah satu interjeksi yang menunjukkan ekspresi rasa senang dan kelegaan penutur.

\section{Jumlah Fi'liyyah}

Jumlah fi'liyyah sebagai suatu jumlah yang subjeknya diawali oleh verba (alKhuli, 1982: 184). Data interjeksi berbentuk jumlah fi'liyyah yang ditemukan peneliti, yaitu astaghfirullâh, insyâ'allâhu, bârakallâhu, jazâkallâhu, syafâkallâhu, tawakkaltu 'alâllâhi, astaui'akumullâh, yarhamuhullâh, nậmadullâha, a'ûdzubillâhi, wazan mâ af'ala (mâ asyadda, mâ ahlâ, mâ a'dhama, mâ ab'atsa, mâ atsqala, mâ arhafa, mâ adzrafa, mâ ab'ada, mâ althafa). Berikut adalah data interjeksi yang berbentuk jumlah fi'liyyah.

Ummu Hâzim : "Turâ... Hal ahbabtahâ. Bi'ainika am biqalbika?”.

Hâzim : "Bi'ainiy, wa qalbiy, wa 'aqliy".

Ummu Hâzim : "syafâkallâh yâ waladîy".

Artinya:

Ibu Hazim : "Lihatlah... apakah engkau mencintainya dengan matamu atau hatimu?". 


\footnotetext{
Hazim : "Dengan mataku, hatiku, dan akalku".

Ibu Hazim : "Semoga Allah menyembuhkanmu wahai Anakku” (Bakatsîr, 1951: 75).
}

Ungkapan Syafakallâh 'semoga Allah menyembuhkanmu' pada data di atas merupakan interjeksi yang berupa jumlah fi'liyyah. Kata syafâ merupakan fi'il madhi (verba perfect pronomina persona 3 laki-laki tunggal). Kata $\mathrm{ka}$ (pronomina persona kedua laki-laki tunggal) yang berfungsi sebagai maf'ûl (objek). Adapun kata Allâh merupakan fấil (agen). Pada di atas interjeksi Syafâkallâh 'semoga Allah menyembuhkanmu' merupakan salah satu interjeksi berbentuk klausa berupa jumlah fi'liyyah yang menunjukkan ekspresi keheranan penutur.

\section{Kesimpulan}

Berdasarkan penelitian yang telah dilakukan oleh peneliti mengenai interjeksi bahasa Arab, maka dapat diambil kesimpulan bahwa dalam bahasa Arab, interjeksi dapat dikelompokkan menjadi bentuk primer, bentuk sekunder, bentuk frasa, dan bentuk klausa. Bentuk primer merupakan bentuk bahasa yang tidak memiliki makna leksikal, biasanya hanya berupa kata-kata pendek dan tiruan bunyi. Bentuk interjeksi primer dalam bahasa Arab adalah bentuk teriakan.

Interjeksi bentuk sekunder dalam bahasa Arab meliputi kata yang berupa ism yang meliputi nomina maushûf (kata yang dapat disifati), nomina shifah (adjektiva), ismu al-fi'li (noun verb) dan berupa harf (partikel) yaitu harfu an-nidâ' (partikel nidâ'). Adapun interjeksi berbentuk frasa dalam bahasa Arab meliputi tiga macam bentuk, yaitu murakkab idhâfiy, murakkab washfiy dan frasa preposisi (jarr majrûr). Sementara itu, interjeksi berbentuk klausa (jumlah) dalam bahasa Arab dapat diklasifikasikan menjadi dua, yaitu jumlah ismiyyah dan jumlah fi'liyyah.

\section{Daftar Rujukan}

Ad-Dahdah, Antoine. Encyclopedia of Arabic Grammar A Dictionary of Arabic In Chart and Tables. Bierut: Librarie du Liban Publishers, 1993.

al-Ghulayaini, Mushthafa. Jâmi'u ad-Durûsi al-'Arabiyyati. Kairo: Dāru Ibnu al-Jawazy, 2010.

Al-Khuli, Muhammad Ali. A Dictionary of Theoretical Linguistics English-Arabic with an Arabic-English Glossary. Librairie du Liban, 1982. 
Ameka, F. In Davis, Crystal. Encyclopedia of Language and Linguistics. 2nd. Edition. Cambridge University Press, 1994.

Ar-Raqr, Abd al-Ganiy. Mu'jam al-Qawâ'id al-'Arabiyyah fi an-Nahwi wa as\}-S\}arfi wa Zuyyila bi al-Imla'. Cetakan Pertama. Damaskus: Dâr al-Qalam, 1986.

Bakatsir, Ali Ahmad. Mismāru Juhhâ. Mesir: Maktabah Mishr, 1951.

Hardiah, Mei. Interjeksi Bahasa Indonesia. Tesis. Yogyakarta: Universitas Gadjah Mada, 2012.

Kesuma, Tri Mastoyo Jati. Pengantar (Metode) Penelitian Bahasa. Yogyakarta: Carasvatibooks, 2007.

Mahfudz, Najib. Al-Masrahiyyât. Mesir: Dâr Asy-Syurûq, 2008.

Moeliono, Anton, M., Hasan Alwi, Soejono Dardjowidjojo, Hans Lapoliwa. Tata Bahasa Baku Bahasa Indonesia. Jakarta: Balai Pustaka, 2003.

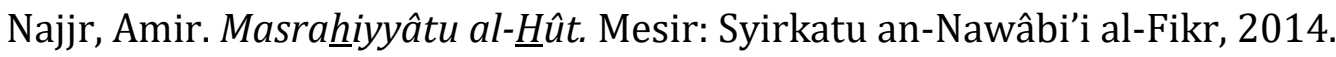

Sa'id, Wannus. Haflau Samri min Ajlihi ㅂazîrân. Beirût : Dâr al-Adâb, 2004.

Wahbah, Majdi dan Kamil al-Muhandis. Mu'jam al-Musthalahât al-Arabiyyah fî al-lugah al-'Arabiyyah. Cetakan kedua. Beirût : Maktabah Lubnân, 1984.

Wierzbicka, Anna. Cross Cultural Pragmatics. The semantics of Human Interaction”. New York: Mouten de Gruyer, 1991.

Wilkins, D. Interjection as Deictics. Journal of Pragmatics. 1992.

Ya'qub, Luis. al-Khuthwât al-Wats^iqah. Mesir: Dâr ar-Rasyâd, 1996.

. Amniyah wa Amniyah. Mesir: Dâr ar-Rasyâd, 1996. 